\title{
RUANG PUBLIK SEBAGAI REPRESENTASI KEBIJAKAN DAN MEDIUM KOMUNIKASI PUBLIK (Studi Komunikasi Kebijakan Ruang Publik Kota Serang)
}

\author{
Abdul Malik \\ Program Studi Sains Komunikasi \\ Fakultas Ilmu Sosial, Ilmu Politik dan Ilmu Hukum Universitas Serang Raya \\ Jl. Raya Serang - Cilegon Km. 05 (Taman Drangong), Serang - Banten \\ Email : Kangdoel2002@yahoo.com

\section{Ringkasan}

Penelitian ini bertujuan menganalisis bagaimana ruang publik dapat menjadi representasi kebijakan publik dan kontribusinya sebagai medium komunikasi publik. Pemilihan locus penelitian ruang publik Kota Serang yang secara objektif merupakan Ibukota Provinsi Banten diharapkan dapat menjadi representasi dan role model kota dengan ruang publik yang ideal. Metode yang digunakan adalah pendekatan kualitatif. Teknik yang dilakukan oleh peneliti adalah survei literatur akademis di bidang keilmuan kebijakan dan komunikasi publik guna memperoleh konsep-konsep yang relevan dengan penelitian. Teknik pengumpulan data melalui penelusuran berbagai sumber dan literatur baik dari dokumen pemerintah maupun pemberitaan media massa cetak dan elektronik, jurnal dan buku-buku yang terkait dengan administrasi pubik dan komunikasi. Hasil penelitian menunjukkan bahwa pengelolaan ruang publik di Kota Serang masih belum merepresentasikan kebijakan yang pro publik, hal ini menjadi tantangan bagi stakeholder kebijakan publik di Kota Serang dalam memformulasikan pengelolaan ruang publik yang ideal selain itu kondisi objektif ruang publik Kota Serang masih belum dapat menjadi medium komunikasi publik yang mampu mendorong kebebasan berfikir dan bertindak egaliter dalam ruang publik.

Kata Kunci: Ruang Publik, Representasi Kebijakan, Komunikasi publik

\section{Abstract}

This study aims to analyze how public space can be a representation of public pride and its contribution as a medium of public communication. The selection of Serus City public space locus research which is objectively the Capital of Banten Province is expected to be a representation and role model for cities with ideal public spaces. The method used is a qualitative approach. The technique carried out by researchers is a survey of academic literature in the field of public policy and communication in order to obtain concepts that are relevant to research. The technique of collecting data is through searching various sources and literature both from government documents and reporting on print and electronic mass media, journals and books related to public administration and communication. The results of the study indicate that the management of public spaces in Serang City still does not represent pro-public policies, this is a challenge for public policy stakeholders in Serang City in formulating the management of ideal public spaces. The objective condition of Serang City's public space still cannot be a medium of public communication that is able to encourage freedom of thought and egalitarian action in the public sphere. Keywords: Public Space, Policy Representation, Public Communication 


\section{PENDAHULUAN}

Penelitian ini membahas tentang ruang publik sebagai medium kebijakan dan komunikasi publik. Pada hakekatnya ruang publik adalah milik masyarakat tanpa terkecuali. Masyarakat sebagai aktor utama mempunyai hak suara publik berdasarkan representasi dan persepsi publik. Keberadaan ruang publik sendiri merupakan ruang atau lahan umum, tempat masyarakat dapat melakukan kegiatan publik fungsional maupun kegiatan sampingan lainnya, yang dapat mengikat suatu komunitas, baik itu kegiatan sehari-hari ataupun berkala (Carr, 1992). Keberadaan ruang publik menjadi bagian penting bagi masyarakat sebagai salah satu upaya untuk mengatasi terjadinya konflik sosial yang mengarah kepada terciptanya disharmoni dan disintegrasi sosial melalui penyediaan ruang terbuka bersama (open public space) seperti : lapangan olah raga, poliklinik, tempat ibadah, lembaga pendidikan, pasar/mall/plaza, taman (E, Budiharjo \& Djoko S.:1999).

Kebutuhan masyarakat terhadap ruang publik sebagai sarana melakukan aktivitas dengan beragam kegiatan secara bersamasama diwujudkan melalui interaksi sosial yang diakomodasi dalam ruang publik sehingga terjadi pembelajaran antara manusia satu dengan yang lain, komunitas satu dengan komunitas yang lain, berlangsung terus menerus hingga akhirnya terdapat kesatuan pemahaman bersama bahwa heterogenitas yang ada dalam satu kota merupakan keniscayaan yang harus dijalani dan diterima bersama-sama (Sunaryo dkk), oleh sebab itu ruang publik menjadi ruang kebebasan bagi masyarakat dalam beraktivitas secara visual maupun fisik.

Ruang publik muncul sebagai suatu wilayah dan bagian yang spesifik dari masyarakat sipil sebagai tempat terjadinya pertukaran komoditas dan kerja sosial yang diatur oleh kaidahnya sendiri. Istilah ruang publik (public sphere) berawal dari pendapat Jurgen Habermas pada tahun 1962 dalam tulisannya yang kemudian diterjemahkan pada tahun 1991 berjudul The Structural Transformation of The Public Sphere. Public sphere adalah ruang terjadinya berbagai diskusi dan debat publik mengenai suatu permasalahan publik, di mana setiap individu sebagai bagian dari publik mempunyai porsi yang sama dalam berpendapat dan dijamin kebebasannya dari intervensi dan restriksi pihak lain sehingga tidak memunculkan hegemoni opini namun menumbuhkan opini publik yang diharapkan akan membantu munculnya kebijakan publik yang adil. Habermas (1991: 105)

Secara ideal, ruang publik memiliki cakupan yang sangat luas dan terbentuk dari proses alamiah interaksi individu dan akumulasi kelompok-kelompok publik, oleh sebab itu dalam kajian kepublikan definisi publik diartikan secara umum, Negara dan masyarakat. Dengan demikian Negara berperan untuk menyediakan ruang publik yang dapat menjadi ruang dimana anggota masyarakat sebagai warga negara mempunyai akses sepenuhnya terhadap semua kegiatan publik, mereka berhak melakukan secara merdeka didalamnya termasuk mengembangkan wacana publik seperti menyampaikan pendapat secara lisan dan tertulis (A.S. Hikam dalam A.S. Culla,1999:123). Berdasarkan kesepakatan formal dan komunikasi massa, ruang publik bertransformasi menjadi ruang interaksi. Dalam hal ini ruang publik dipandang tidak terbentuk dari sebuah aktivitas atau proses komunikasi akan tetapi berdasarkan adanya akses (Brodin, 2006) artinya perilaku dan komunikasi yang dilakukan oleh berbagai individu berorientasi terhadap orang lain melalui pemanfaatan berbagai akses bagi publik sebagai subjek.

Terdapat tiga prinsip ruang publik yaitu : 1)Akses yang mudah terhadap informasi. Teknologi masa kini memungkinkan anggota masyarakat untuk mendapatkan akses terhadap informasi. Pada masa awal ruang publik berkembang, akses ini hanya dimiliki oleh sebagian kecil kelompok masyarakat, dalam hal ini kaum 
borjuis. Keberadaan publik sphere kemudian semakin berkembang seiring dengan pesatnya perkembangan media massa. Media massa semakin memungkinkan setiap anggota masyarakat untuk menyampaikan ide maupun gagasannya untuk dibicarakan di forumforum publik; 2)Tidak ada perlakuan istimewa (privilege) terhadap peserta diskusi (partisipan). Tidak adanya privelege diartikan bahwa setiap anggota masyarakat memiliki kesetaraan dalam proses wicara. Tidak ada kelompok yang lebih dominan atas kelompok lainnya; 3)Peserta/partisipan mengemukakan alasan rasional dalam berdiskusi mencari konsensus. Alasan rasional menjadi syarat penting terwujudnya ruang publik yang baik. Rasionalitas dalam debat akan menjamin bahwasanya debat yang berlangsung adalah debat yang dapat dipertanggungjawabkan dengan sumber informasi yang benar dan tepat, sehingga dapat menghindarkan terjadinya debat kusir ataupun pertarungan emosional antar partisipan. (Rouper, Toulouse, 1998 dalam Saleh, 2004)

Peranan ruang publik (Carmona, et al (2008:9) terdiri dari aspek-aspek sebagai berikut yaitu : 1)Ekonomi, yaitu memberi pengaruh positif pada properti dan mendorong performa regional; 2)Kesehatan yaitu mendorong masyarakat aktif melakukan gerak fisik dan menyediakan ruang informal dan formal bagi kegiatan olahraga; 3)Sosial yaitu menyediakan ruang bagi interaksi dan pembelajaran sosial pada segala usia, mengurangi resiko terjadinya kejahatan dan sikap anti sosial, Mengurangi dominasi kendaraan bermotor sehingga angka kecelakaan dapat berkurang dan mendorong dan meningkatkan kehidupan berkomunitas; 4).Lingkungan yaitu mendorong terwujudnya transportasi berkelanjutan, meningkatkan kualitas udara, menciptakan kesempata untuk berkembangkanya keanekaragaman hayati.

Berbagai penelitian yang secara umum mengkaji ruang publik sudah dilakukan diantaranya (Sulistyo, 2012; Kusumodewi, 2015; Garau, Tieben, Radovic, Crowther, 2016). Kemudian beberapa penelitian yang membahas secara khusus konsep ruang publik sebagai sarana komunikasi, dimensi sosial dan interaksi sosial (Forgas, 2000; Altman, 2003; Anita dkk, 2012; Behrad dan Bahrami, 2015; Jamaludin, 2018). Selanjutnya Yuliastuti (2018) dalam penelitiannya mengemukakan bahwa ruang publik khususnya taman dan ruang hijau memiliki nilai dan peranan untuk melakukan interaksi sosial sesuai dengan fungsinya sebagai ruang rekreasi dan kegiatan di luar ruangan. Meskipun demikian, kajian ruang publik masih memerlukan diskursus tentang bagaimana posisi dan objek ruang publik dalam dimensi kebijakan dan komunikasi publik. Pemaknaaan ruang publik sebagai alat atau mediasi antara publik dan negara yang mampu memberikan ruang bagi terciptanya nilai-nilai manifestasi kondisi publik sekaligus menempatkan dan memberikan ruang publik secara ideal baik dari konteks kebijakan pemerintah maupun komunikasi publik.

Dalam konteks penelitian ini, batasan dan tipologi ruang terbuka publik yaitu taman-taman publik (public parks), lapangan dan plaza (square and plaza), taman peringatan (memorial parks), pasar (markets), jalan (streets), lapangan bermain (playground), ruang terbuka untuk masyarakat (community open spaces), jalan hijau dan jalan taman (green ways and park ways), atrium/pasar tertutup (atrium /indoor markets place), pasar/pusat perbelanjaan pusat kota (market place/down town shopping center), tepi laut (water fronts) (Huat et al, 1992).

Kondisi eksisiting ruang publik di Kota Serang secara objektif masih belum merepresentasikan tentang makna dan fungsi ruang publik yang ideal baik dari aspek kebijakan maupun komunikasi publik. Tidak berfungsinya alun-alun Kota Serang sebagai ruang terbuka publik (Medium Com, 03 Juli 2016) dan telah beralih fungsi menjadi tempat berjualan pedagang kaki lima menunjukkan belum adanya prioritas kebijakan dari pemerintah dan tidak berfungsinya ruang 
publik sebagai arena dan diskursus komunikasi publik. Selain itu beberapa tempat ruang publik lainnya yang sudah beralih fungsi seperti kawasan Stadion Maulana Yusuf Ciceri Serang dan Taman Sari Serang serta Taman K3 Jendral Sudirman yang sekarang beralih fungsi menjadi Kantor Kominfo. Keterbatasan sarana dan prasarana publik seperti minimnya taman dan ruang terbuka untuk masyarakat di kawasan perkotaan menjadi indikasi perlunya dilakukan evaluasi terhadap kebijakan pemerintah dalam pemenuhan ketersediaan ruang publik, kondisi pasar sebagai pusat interaksi sosial dan transaksi ekonomi publik masih belum mencerminkan fungsi pasar sebagai media komunikasi publik, kondisi pasar yang kotor dan tidak tertata (Radar Banten, 28 April 2018).

Penelitian ini bertujuan menganalisis bagaimana ruang publik dapat menjadi representasi kebijakan publik dan kontribusinya sebagai medium komunikasi publik. Pemilihan locus penelitian ruang publik Kota Serang yang secara objektif merupakan Ibukota Provinsi Banten diharapkan dapat menjadi representasi dan role model kota dengan ruang publik yang ideal.

\section{METODE PENELITIAN}

Metode yang digunakan adalah pendekatan kualitatif. Teknik yang dilakukan oleh peneliti adalah survei literatur akademis di bidang keilmuan kebijakan publik dan komunikasi guna memperoleh konsep-konsep yang relevan dengan penelitian. Teknik pengumpulan data melalui penelusuran berbagai sumber dan literatur baik dari dokumen pemerintah maupun pemberitaan media massa cetak dan elektronik, jurnal dan buku-buku yang terkait dengan administrasi pubik dan komunikasi. Data sekunder tersebut diolah dan dideskripsikan dalam bentuk narasi sesuai dengan kebutuhan data. Selanjutnya dilakukan proses analisis data berdasarkan teori dan konsep kebijakan dan komunikasi publik serta selanjutnya dilakukan proses intrepretasi data

\section{HASIL DAN PEMBAHASAN \\ Representasi Kebijakan Ruang Publik}

Dalam kajian administrasi publik, konsep publik dikemukakan Frederickson (1997:30) yang melihat publik dalam lima perspektif yaitu : 1)publik sebagai kelompok kepentingan; 2)publik sebagai pemilih rasional; 3)publik sebagai representasi masyarakat; 4)publik sebagai konsumen, dan 5)publik sebagai warga negara. Dalam hal ini publik dipandang sebagai individu yang memiliki multi perspektif dan independensi dalam melakukan berbagai tindakan sosial yang memiliki dampak terhadap orang lain.

Konteks kebijakan publik melihat eksistensi ruang publik sangat dipengaruhi oleh konteks governance yakni adanya pembagian kekuasaan antara negara, pasar, dan masyarakat secara lebih luas (Wasisto, 2016), Ruang publik (public space) merupakan salah satu sarana fisik yang dalam pembangunannya memerlukan sebuah kebijakan publik. Ruang publik merupakan termasuk barang publik (public goods) dan digunakan untuk kepentingan publik. Barang publik didefinisikan sebagai "Public goods are those for which consumption by one individual dose not reduce availability to others. Within typical urban economy, there is a whole range of goods that contain elements of 'publicness' in that their production, while not necessarily benefiting everyone equally, does allow consumers other than those willing and able to pay to gain considerable benefit from their use" (Clark et al, 2009)

Konteks kebijakan ruang publik Kota Serang diatur menurut Peraturan Daerah Kota Serang Nomor 3 Tahun 2013 tentang pengelolaan ruang terbuka hijau yang menimbang peraturan daerah Kota Serang nomor 6 tahun 2011 tentang rencana tata ruang wilayah kota serang tahun 2010-2030, dijelaskan bahwa perlu adanya penetapan rencana pengelolaan ruang terbuka hijau sebagai dasar bagi pencapaian proporsi $30 \%$ 
(tiga puluh persen) dari luas wilayah kota, ruang adalah wadah yang meliputi ruang daratan, ruang laut, dan ruang udara termasuk ruang didalam bumi sebagai satu kesatuan wilayah, tempat manusia dan makhluk lain hidup, melakukan kegiatan, dan memelihara kelangsungan kehidupannya. RTH terbagi menjadi dua bagian yaitu RTH Privat dan RTH Publik. RTH Privat adalah RTH milik institusi tertentu atau orang perseorangan yang pemanfaaatannya untuk kalangan teerbatas antara lain berupa kebun atau halaman rumah/gedung milik masyarakat/ swasta yang ditanami tumbuhan. Sedangkan RTH publik adalah RTH yang dimiliki dan dikelola oleh pemerintah daerah yang dimanfaatkan untuk kepentingan masyarakat secara umum.

Kebijakan normatif tersebut pada tataran praktis belum dapat merepresentasikan makna dan fungsi objek ruang publik bagi kepentingan publik. Hal ini disebabkan secara substansial makna ruang publik hanya terbatas pada pemahaman tipologi ruang terbuka hijau privat dan ruang terbuka hijau publik sehingga ruang publik sebagai locus kebijakan secara khusus tidak dibahas dan menjadi objek kajian kebijakan. Ruang publik sebagai arena publik untuk dapat memberikan fungsi representasi akses, control dan voice belum dapat diimplementasikan secara optimal. Permasalahan tersebut disebabkan rendahnya kemampuan berinovasi (ability to innovate) dan kemauan berinovasi (willingnes to inovate), Di sisi lain kebijakan publik sebagai instrumen yang berfungsi menyatukan pemerintah dan masyarakat belum berjalan secara optimal disebabkan karena masih terdapat tumpang tindih kebijakan yang dikeluarkan oleh instansi pembuat kebijakan yang berbeda (Sururi, 2016) sehingga mendorong kebijakan yang mampu mereprentasikan kepentingan publik dengan menyediakan sarana dan prasarana ruang publik menjadi keniscayaan bagi Pemerintah Kota Serang. Mendorong kebijakan ruang publik yang inovatif menjadi prasyarat mutlak inovasi kebijakan publik adalah terwujudnya gagasan dan ide dari pejabat publik sebagai entrypoint diimplementasikannya berbagai programprogram dan kebijakan (Sururi, $2018: 28$ ).

\section{Ruang Publik sebagai Medium Komunikasi Publik}

Pembahasan mengenai ruang publik sendiri lebih mengarahkan pada bentuk arena inklusif yang memungkinkan adanya partisipasi meluas, egaliter dan juga inklusif sehingga mendorong masyarakat untuk membicarakan masalah kekinian ruang publik yang dideskripsikan dalam tiga ranah penting yakni 1)ruang publik sebagai arena. Makna tersebut mengindikasikan bahwa ruang publik menyediakan basis komunikasi antar masyarakat. 2)ruang publik itu adalah publik itu sendiri. Makna tersebut mengindikasikan bahwa publik adalah aktor penting dalam menjalankan demokrasi dari tingkatan akar rumput. 3)ruang publik adalah agen. Maksudnya ruang publik itu merupakan agen/alat penting dalam menyampaikan aspirasi dari akar rumpur menuju bawah (Schuler \& Day, 2004: 4-6 dalam Wasisto, 2016).

Pertanyaan substansial yang harus dikemukakan adalah apakah ruang publik dapat menjadi arena dan diskursus komunikasi publik atau dengan kata lain apakah publik mampu melakukan komunikasi yang mampu mendorong kebebasan berfikir dan bertindak secara egaliter dalam ruang publik. Bahwa ruang dianggap publik dapat diakses oleh publik tanpa batasan dan menumbuhkan komunikasi dan interaksi. Konsep ruang publik merupakan bagian vital dalam negara demokratis. Demokrasi dapat berjalan dengan baik jika dalam suatu negara terdapat ruang publik yang egaliter dimana setiap orang memiliki kesempatan yang sama untuk berpartisipasi dan menyampaikan idenya (Littlejohn, 2009).

Sedangkan Menurut Carr (1992) pemanfaatan ruang terbuka publik harus memiliki tiga nilai utama, yaitu responsif, demokratis dan bermakna. Selanjutnya 
disebutkan bahwa ruang publik meliputi aspek kebutuhan (needs), aspek hak (rights), dan aspek makna (meaning). Selanjutnya tiga aspek tersebut akan berperan secara baik jika mengandung unsur : 1).Kebutuhan (Human Needs), yang terdiri dari kenyamanan, relaksasi, aktivitas pasif, aktivitas aktif dan discovery; 2).Hak Penggunaan (Rights of use), yaitu pengakuan kebebasan beraktivitas di ruang publik yang terdiri dari akses dan kemudahan, kemudahan bergerak, pengakuan penggunaan ruang, serta perubahan; 3). Makna (Meaning), merupakan aspek yang dikaji dari aspek fisik dan non fisik serta keterkaitan sejarah dan sosial politik dan budaya, meliputi mudah dikenali, keterkaitan, hubungan individu, hubungan kelompok, hubungan dengan lapisan masyarakat yang lebih luas seperti simbol dari keberlangsungan sejarah, kepentingan politik, sosial budaya, ekonomi dan simbol kekuasaan, hubungan aspek biologis dan psikologis, hubungan dengan faktor lain seperti iklim. Dengan demikian dapat dikatakan bahwa dimensi komunikasi publik terkait dengan ruang publik yang dapat memainkan peranan penting sebagai tempat pertemuan dan wadah gerakan sosial, ruang publik mempunyai kontribusi terhadap aktivitas sosial masyarakat (Madanipour, 1996).

\section{KESIMPULAN}

Ruang publik didedikasikan untuk kebutuhan publik dan menjadi tempat bertemunya beragam kepentingan publik. Interaksi sosial, ekonomi dan politik yang dibangun dalam ruang publik mensyaratkan adanya makna dan fungsi akses, control dan voice. Pengelolaan ruang publik di Kota Serang masih belum merepresentasikan kebijakan yang pro publik, hal ini menjadi tantangan bagi stakeholder kebijakan publik di Kota Serang dalam memformulasikan pengelolaan ruang publik yang ideal. Kondisi objektif ruang publik Kota Serang masih belum dapat menjadi medium komunikasi publik yang mampu mendorong kebebasan berfikir dan bertindak egaliter dalam ruang publik.

\section{DAFTAR PUSTAKA}

Anita Juarni, Gustya Fendy, Erawati Lucy Rahayu, Sukma Mega Dewi, 2012. Kajian Terhadap Ruang Publik Sebagai Sarana Interaksi Warga di Kampung Muararajeun Lama, Bandung. Reka Karsa Jurnal Online Institute Teknologi Nasional, Volume 1 Nomor 1, Halaman 1-12

Behrad B. and Bahrami B. 2015. The Impact of Public Spaces Physical Quality in Residential Complexes on Improving User's Social Interactions; Case Study: Pavan Residential Complex of Sanandaj, Iran. J. Civil Eng. Urban., 5 (2): 89-93.

Budiharjo, Eko dan Djoko Sujarto, 1999, Kota Berkelanjutan, Alumni, Bandung

Brodin, 2006. Public Space. Exploration of a Concept. Western Political Science Association Annual meeting Albuquerque, 16 - 18 March 2006

Carmona, et al 2008. Public Space : The Management Dimension. Routledge, Taylor \& Francis Group. New York, USA

Carr, Stephen. 1992. Public Space. Cambridge: Cambridge University Press

Cochran, Clark., E, Meyer, Lawrence., C, Carr, T., Cayer, Joseph., N. (2009). American Public Policy. An Introduction. Ninth Ed. Canada: Wadsworth, Cengage Learning. pp.104, 7. 
Huat, Beng, Chua., Edwards, Norman. (1992). Public Space: Design, Use and Management. Singapore: Singapore University Press.pp. 2.

Habermas Jurgen, 1991. The Structural Transformation of The Public Sphere. Public sphere, First MIT Press paperback edition, 1991. This translation 1989 Massachusetts Institute of Technology. This work originally appeared in German under the Title Strukl ttwai dedle rOflet lliclreil, 1962 Hermann Luchterhand Verlag, Darrnstadt and Neuwied, Federal Republic of Germany

Hikam, Muhammad As., 1991, Negara, Masyarakat Sipil dan Gerakan Keagamaan Dalam politik Indonesia, Prisma No.3, LP3ES, Jakarta

Littlejohn, Stephen W. \& Foss, K.A (Ed). 2009. Encyclopedia of Communication Theory. California : Sage Publication

Madanipour, A. (1996) Design of Urban Space: An Inquiry into a SocialSpatial Process. Chichester, UK: John Wiley \& Sons.

Saleh, Rahmat. 2004. Potensi Media sebagai Ruang Publik. Jurnal Thesis Volume III/No.2, Mei-Agustus 2004, Jurnal Penelitian Ilmu Komunikasi Departemen Ilmu Komunikasi UI.

Sunaryo Rony Gunawan, Soewarno Nindyo, Ika Putra, Setiawan Bakti. Posisi Ruang Publik dalam Transformasi Konsepsi Urbanitas Kota Indonesia.

Sulistyo Broto W, 2012. Diferensiasi dan Redefinisi Ruang Terbuka Publik Kota melalui pemaknaan jiwa tempat
(Spirit Of Place) (Studi Kasus : Taman Bungkul Surabaya), Jurnal Iptek Volume 16 Nomor 1, Halaman 9-16, Mei 2012.

Sururi, Ahmad, 2016. Inovasi Kebijakan publik (Tinjauan Konseptual dan Empiris), Jurnal Sawala, Volume 4 Nomor 3, 2016.

Sururi, Ahmad, 2018. Collaborative Governance sebagai Inovasi Kebijakan Strategis (Studi Revitalisasi Kawasan Wisata Cagar Budaya Banten Lama), Jurnal Humanika Volume 25 Nomor 1, 2018.

Yuliastuti Nany, Sukmawati Annisa Mu'awanah, Purwoningsih, 2018. Utilization Of Social Facilities To Reinforce Social Interaction in formal housing, Archnet-IJAR: International Journal Of Architectural Research, Volume 12 Issue 1 - March 2018 - (134-151) Regular Section

Wasisto, 2016. Ruang Publik, Aktivisme Online dan Kelas Menengah Indonesia. Paper disampaikan pada "Unbreakable Discussion Series: Public Sphere and Online Activism" di Epikurian Cafe, 9 Januari 2016.

Sumber Lain :

https://medium.com/planologi-2015/tidakberfungsinya-alun-alun-kota-serang-sebagairuang-terbuka-publik-29ebe08253a1 (Diakses pada tanggal 03 Oktober 2018)

https://www.radarbanten.co.id/kondisi-pasarinduk-rau-semakin-semrawut-pkl-bandelsampah-menumpuk (Diakses pada tanggal 09 September 2018)

Peraturan Daerah Kota Serang Nomor 6 Tahun 2011 tentang Ruang Terbuka Hijau. 